\title{
GARDNER'S SYNDROME AS THE FIRST MANIFESTATION OF FAP IN PATIENT WITH METASTATIC RECTAL CANCER - AN EXTREMELY RARE OCCURRENCE
}

\author{
J Clarke 2,3, S Islam 1,3凶, S Medford ${ }^{2,3}$, S Juman ${ }^{2,3}$, P Harnarayan 1,3 (D) V Naraynsingh ${ }^{3}$ \\ ${ }^{1}$ Department of Surgery, San Fernando Teaching Hospital, SWRHA, Trinidad \& Tobago, Caribbean \\ ${ }^{2}$ Department of Otolaryngology, Head and Neck Surgery, San Fernando Teaching Hospital, Trinidad \& Tobago, \\ Caribbean \\ ${ }^{3}$ Department of the Clinical Surgical Science, University of the West Indies, St. Augustine, Trinidad and Tobago, \\ Caribbean
}

Received 5 August 2021

Accepted 19 August 2021

Published 31 August 2021

\section{Corresponding Author}

Dr. Shariful Islam,

sss1201198@yahoo.com

DOI

10.29121/granthaalayah.v9.i8.2021. 4188

Funding: This research received no specific grant from any funding agency in the public, commercial, or not-for-profit sectors.

Copyright: (C) 2021 The Author(s). This is an open access article distributed under the terms of the Creative Commons Attribution License, which permits unrestricted use, distribution, and reproduction in any medium, provided the original author and source are credited.

\section{ABSTRACT}

Familial adenomatous polyposis [FAP] is a rare autosomal disorder. FAP presenting with Gardner syndrome is even rarer. Gardner syndrome as the first manifestation of FAP without any prior family history is even scarcer. We report the case of a 32 years healthy male referred to our otolaryngology clinic with a neck mass and ultimately diagnosed with a case of Gardner syndrome with FAP and advanced rectal Cancer. The patient had a successful gastrointestinal surgery with follow up chemotherapy. Subsequently the patient was followed up at the gastroenterology, oncology and surgical clinic. Literature searched was done and the extra colonic manifestations of the diseases are highlighted in our discussion.

Keywords: Gardener's Syndrome, Extra-Colonic Manifestations, Fap (Familial Adenomatous Polyposis)

\section{INTRODUCTION}

Gardner's syndrome is a rare variant of familial adenomatous polyposis [FAP] which presents with many extracolonic manifestations, such as osteomas of the skull and desmoid tumours of the neck Cankaya AB et al. (2012), Seehra et al. (2016), Fotiadis C et al. (2005). In the United States, the incidence of FAP is 1 case per 8000 people, whereas the incidence of Gardner's syndrome is one person per million population Dermatologic Manifestations of Gardner Syndrome (2021). Gardner's syndrome is an autosomal dominant disorder localized to the long arm of chromosome 5 [5q21-22] Cankaya AB et al. (2012). These patients may present to the otolaryngologist, who must be cognizant of the diagnosis, as patients with Gardner's syndrome have an almost $100 \%$ conversion rate of colonic polyps to adenocarcinoma.

This case report is of young man who was diagnosed with Gardner's syndrome based on his clinical ENT findings. The extracolonic features of Gardner's syndrome will be reviewed in the discussion.

\section{CASE REPORT}

A 32-year-old male presented to the Ear, Nose and Throat (ENT) department complaining of a right sided neck mass which was slowly becoming larger over 
the last three months. Of note the patient had been seen in the ENT department the previous year for a fibroepithelial polyp to the right lateral border of his tongue. The patient denied any current history of trauma, infection, weight loss, per rectal bleeding, melena, smoking or drinking. He also denied off any family history of polyposis or colorectal malignancy. The mass was $4 \times 5 \mathrm{~cm}$ in size, located in Level $\mathrm{V}$ on the right side of the neck and was painless and fixed to deep structures. The patient also had several 'bony overgrowths' located along the body of the mandible bilaterally and in his skull. Examination of the rest of the head and neck region showed no further abnormalities.

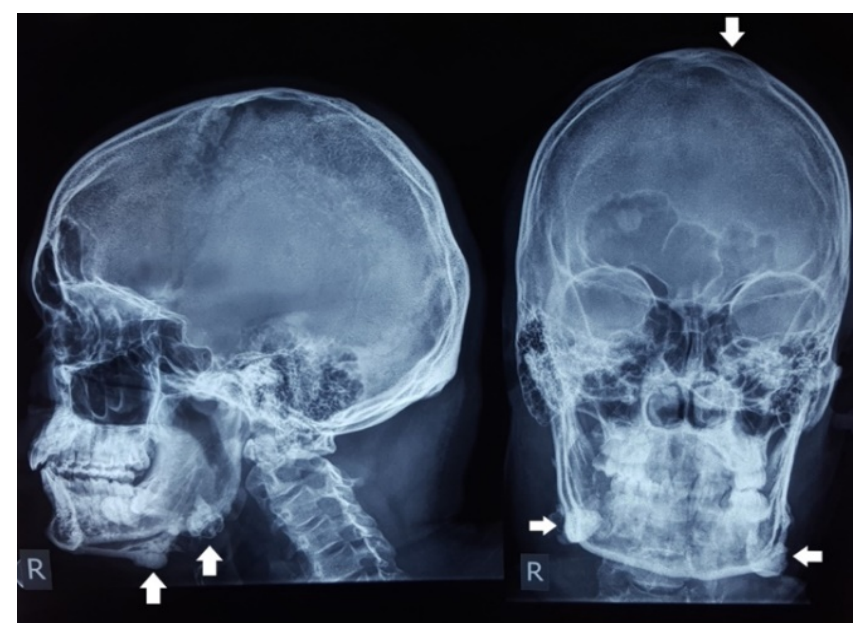

Figure 1 Skull X rays (AP \& Lateral) showing multiple osteomas of the skull (white arrows)

$\mathrm{X}$ rays were done initially of the skull which showed several osteomas present in the region of the mandible and the skull (Figure 1). A CT scan of the neck and head showed a $4.6 \times 5.3 \mathrm{~cm}$ mass located in the right side of the neck deep to the sternocleidomastoid muscle effacing the carotid sheath suggestive of fibromatoses (Figure 2). An image guided Tru-cut biopsy of the neck mass was performed and the histology revealed sheets of thick collagen bundles suggestive of a nuchal-type fibroma.

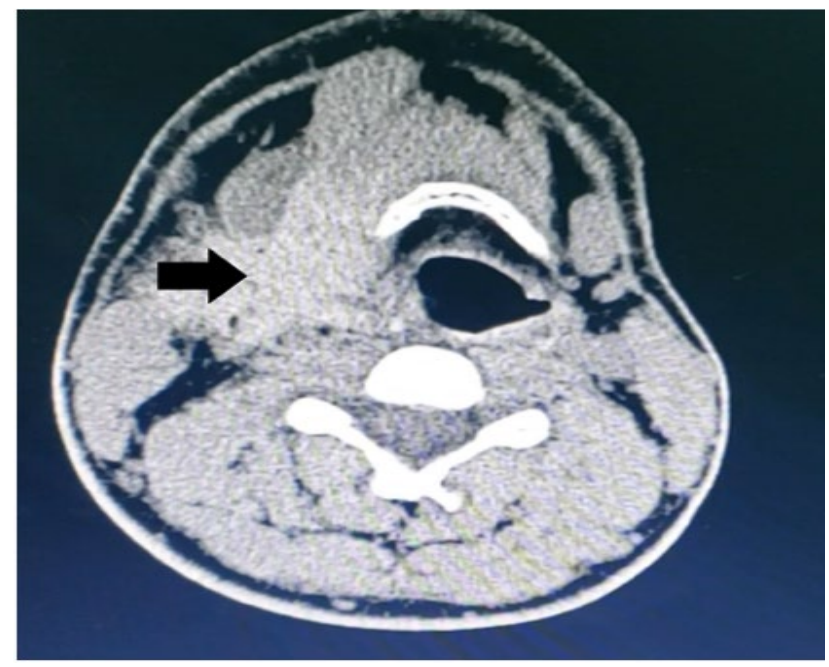

Figure 2 CT scan of head and neck showing ill-defined mass suggestive of fibromatoses (Black Arrow) 
Given the clinical picture a diagnosis of Gardner's syndrome was entertained. The patient was immediately referred to Gastroenterology for assessment. A colonoscopy was done with numerous tubulars and tubullo-villous polyps identified throughout the colon; however invasive adenocarcinoma was identified in a villous polyp present in the rectum. An upper GI endoscopy also revealed a fundic gland polyp of the stomach and adenomas of the duodenum and jejunum. The patient was then referred to General Surgery. A CT scan of the abdomen, and chest with intravenous contrast revealed polypoidal lesions in the upper and lower rectum (Figure 3) with bi-lobar liver metastasis.

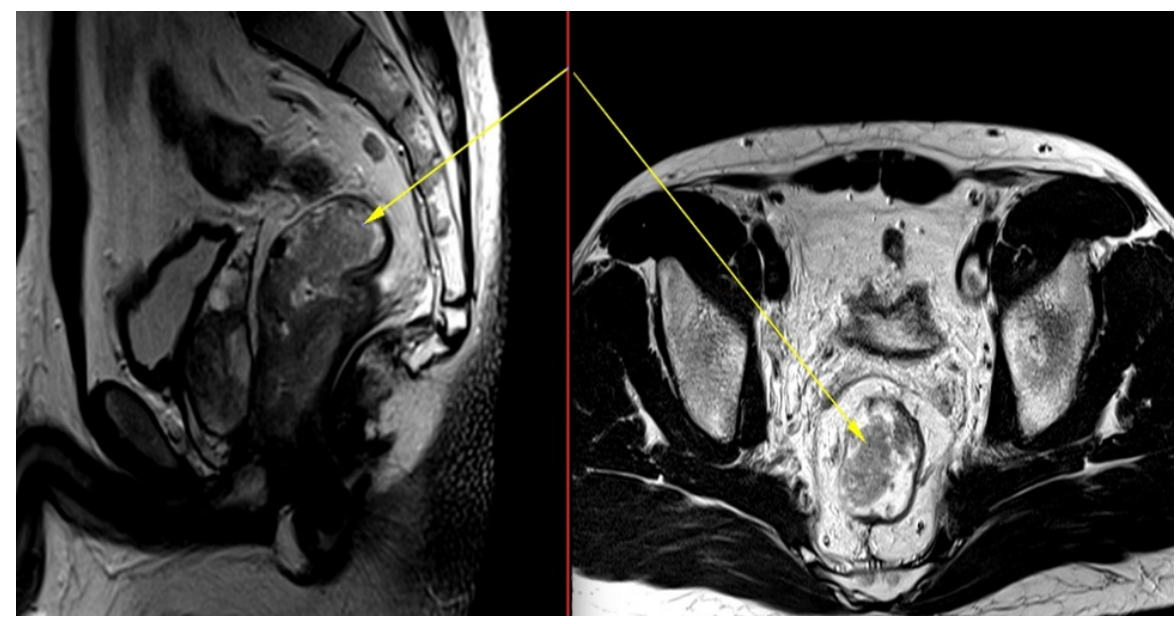

Figure 3 T2 sagittal/axial sequencing demonstrating a polypoidal type lesion with smaller lesions seen distally within the lower rectum (yellow arrows).

The case was discussed at our multidisciplinary team meeting. Considering his age and functional status, decision of upfront surgery followed by adjuvant chemotherapy was made. The patient was consented and a pan-procto-colectomy (Figure 4) with ileo-anal J pouch anastomosis was performed. The patient recovered well from the surgery. The case was presented again in the MDT meeting with the final histo-pathological report, and a decision was made for adjuvant chemotherapy.

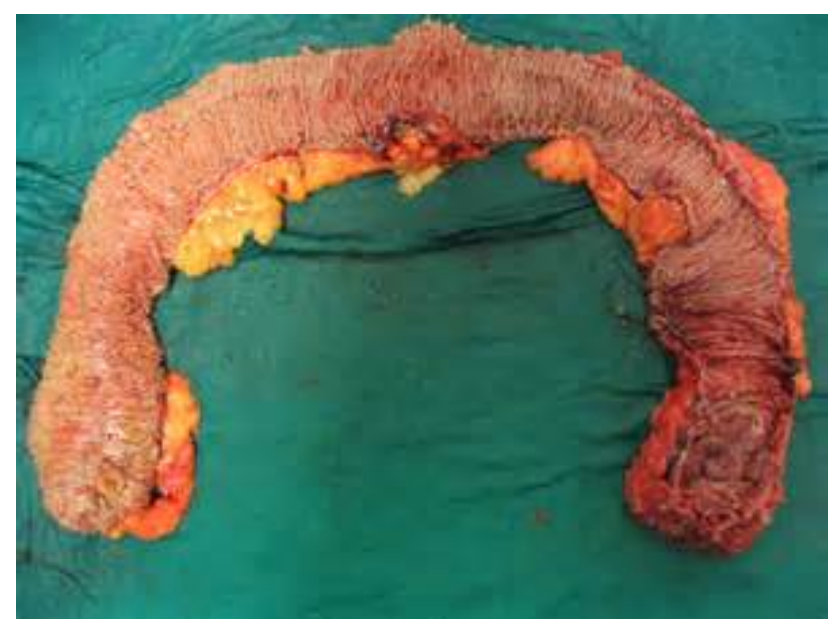

Figure 4 Specimen of colon \& rectum showing extensive polyposis

He was also followed up at the oncology, Gastroenterology and Surgical outpatient clinic. At two years of follow-up, the patient was doing well and completed his chemotherapy. A repeat CT scan of the abdomen and pelvis revealed 
that the liver lesions are still there but have decreased in size. Detailed screening of the family failed to detect any further pathology.

\section{DISCUSSION}

Gardner's syndrome is caused by a dominantly inherited mutation in the APC gene localised on chromosome 5q21-q22 Dermatologic Manifestations of Gardner Syndrome (2021), Colella DM et al. (2016), Charifa A et al. (2021). Mutations can occur anywhere within the gene and using current technology these can be identified in about $85 \%$ of individuals with Familial Adenomatosis Polypoli (FAP) by analysing a blood sample. The majority of individuals with FAP have a family history of the condition but as many as 30\% may have a new dominant mutation and be the first affected member of their family. However, in families where a mutation cannot be identified, screening of the bowel by colonoscopy and endoscopy is indicated. All family members at $50 \%$ risk have to be screened from the age of twelve. The polyps usually develop in the teenage years but if no polyps have developed by the age of forty then screening can be discontinued. Our patient unfortunately is the first person in his entire family to be diagnosed with it.

Assessment by an otolaryngologist is critical because most of the extracolonic manifestations of Gardner's syndrome present in the head and neck region. One feature necessary to make the diagnosis of Gardner's syndrome is multiple osteomas which vary from slight thickening to large masses and may affect all parts of the skeleton Cankaya AB et al. (2012), Seehra J et al. (2016), Yu D et al. (2018). Commonly affected sites include the angle of the mandible, para-nasal sinuses and, skull. Osteomas may present earlier even before radiographic evidence of colonic polyposis. In the present case, multiple osteomas of the mandible and skull were noted. Thirty percent of patients with Gardner's syndrome show various dental anomalies. Commonly seen abnormalities are impacted teeth, hypercementosis, congenitally missing teeth and supernumerary teeth Arora (2014), Singla (2015). Other defects such as tapered roots of posterior teeth, fused roots of the first and second molars, long and dentigerous cysts, and multiple caries are also seen. In the index case multiple impacted teeth were noted Arora (2014), Singla (2015).

Many soft tissue tumours are also associated with this syndrome. Epidermoid cysts are the most common benign cutaneous lesions observed in this syndrome Yu D et al. (2018). They may occur on the face, extremities, and scalp and are commonly seen around puberty. These cysts are usually asymptomatic but may become inflamed. Desmoid tumours account for $3.5 \%$ of all fibrous tissue tumours and $0.03 \%$ of all neoplasms Verma P et al. (2016). They are locally aggressive but commonly do not metastasize. They are also considered locally invasive, nonencapsulated, non-malignant, and $10 \%$ of tumours may occur in skin of anterior abdominal wall or intra-abdominally Singla (2015). Fibromatoses is quite common in patients with Gardner's syndrome. It is commonly located in the abdominal cavity i.e- in the mesentery or in the incisional scars Diwan AH et al. (2000). Contrary to the above, our patient presented with a nuchal-type fibroma in the neck.

Approximately $75 \%$ of FAP patients have congenital hypertrophy of the retinal pigment epithelium (CHRPE), and it is easily detected on ophthalmoscopy examination.

It is very rare to have more than three of these lesions in normal individuals. However, using the presence of CHRPE as a marker for FAP in at risk individuals is difficult because of the inter-familial differences in predisposition to CHRPE.

Adrenal adenoma, papillary carcinoma, hepatocellular carcinoma, adenocarcinoma, and osteosarcoma have also been documented. It is important to 
note that polyps may develop throughout the gastro-intestinal tract. Duodenal cancer occurs in about $5 \%$ of FAP patients following colectomy.

\section{CONCLUSION}

This case is representative of the classical picture of Gardner's syndrome which is usually overlooked by many in the medical profession. The gravity of this syndrome lies in the fact that intestinal polyps have a $100 \%$ chance of malignant transformation. The clinician must therefore be cognizant of the colonic and extracolonic manifestations which may help in halting this dreaded disease from further progression. The patient also needs to have aggressive lifelong follow-up since there is a constant threat to their lives at any age.

\section{CONFLICTS OF INTEREST}

The authors of this paper declare no conflicts of interest.

J Clarke 2,3, S Islam 1,3, S Medford 2,3, S Juman 2,3, P Harnarayan1,3, V Naraynsingh 3

\section{AUTHOR CONTRIBUTION}

Author JC, SI, SM, and SJ authors have contributed in designing and organizing to write manuscript, collecting data whereas author $\mathrm{PH}$ and VN have helped in critical analysing the manuscript. The final version of the manuscript was approved by all authors.

\section{REFERENCES}

Arora P SP (2014). Gardener Syndrome: A Rare Case Report. Dentistry [Internet]; 05(04). Retrieved from https://doi.org/10.4172/2161-1122.1000233

Cankaya AB, Erdem MA, Isler SC, Cifter M, Olgac V, Kasapoglu C, et al. Oral and Maxillofacial (2012) Considerations in Gardner's Syndrome. Int J Med Sci; 9(2):137-41. Retrieved from https://doi.org/10.7150/ijms.3989

Charifa A, Jamil RT, Zhang X. (2021) Gardner Syndrome. In: StatPearls [Internet]. Treasure Island (FL): Stat Pearls Publishing. Retrieved from http://www.ncbi.nlm.nih.gov/books/NBK482342/

Colella DM, Patel N, Israr F, Sobrado J. (2016) A Rare Case Report of Gardner Syndrome: A Familial Adenomatous Polyposis Variant: 2585. Off J Am Coll Gastroenterol ACG. Oct;111:S1303. Retrieved from https://doi.org/10.14309/00000434-201610001-02585

Dermatologic Manifestations of Gardner Syndrome (2021): Background, Pathophysiology, Etiology. Apr 5. Retrieved from https://emedicine.medscape.com/article/1093486-overview

Diwan AH, Graves ED, King JAC, Horenstein MG. (2000) Nuchal-Type Fibroma in Two Related Patients With Gardner's Syndrome. Am J Surg Pathol. Nov;24(11):1563-7. Retrieved from https://doi.org/10.1097/00000478200011000-00015

Fotiadis C, Tsekouras D, Antonakis P, Sfiniadakis J, Genetzakis M, Zografos G. (2005) Gardner's syndrome: A case report and review of the literature. World J Gastroenterol. Sep 14;11(34):5408-11. Retrieved from https://doi.org/10.3748/wjg.v11.i34.5408 
Seehra J, Patel S, Bryant C. (2016) Gardner's Syndrome Revisited: A Clinical Case and Overview of the Literature. J Orthod. Mar; 43(1):59-64. Retrieved from https://doi.org/10.1179/1465313315Y.0000000008

Singla. (2015) Gardner's syndrome: A case report and review of literature [Internet].; vol- 27; issue 4; page 625-628, Retrieved from https://doi.org/10.4103/0972-1363.188779

Verma P, Surya V, Kadam S, Umarji HR. (2016) Classical presentation of Gardner's syndrome in an Indian patient: A case report. Contemp Clin Dent;7(2):27780. Retrieved from https://doi.org/10.4103/0976-237X.183063

Yu D, Cw BN, Zhu H, Liu J, Lin Y. (2018) Bone and dental abnormalities as first signs of familial Gardner's syndrome in a Chinese family: a literature review and a case report. médecine/sciences. Oct 1;34:20-5. Retrieved from https://doi.org/10.1051/medsci/201834f104 